\title{
KEANEKARAGAMAN HAYATI FLORA DAN FAUNA DI KAWASAN TAMAN NASIONAL BUKIT BARISAN SELATAN (TNBBS) RESORT MERPAS BINTUHAN KABUPATEN KAUR
}

\author{
Azis Abdul Malik ${ }^{1}$, Joko Prayudha $\mathrm{S}^{2}$, Ririn Anggreany ${ }^{3}$, May Wulan Sari ${ }^{4}$, Ahmad Walid \\ ${ }_{1,3,4,5}$ Program Studi Pendidikan IPA , Institut Agama Islam Negeri (IAIN) Bengkulu \\ Jl. Raden Fatah Pagar Dewa, Tlp (0736) 51276 Bengkulu (383211), Indonesia \\ ${ }^{2}$ Program Studi Pendidikan Bahasa Inggris, Universitas Bengkulu
}

Jl. WR Supratman Kel. Kandang Limun, Kec. Muara Bangkahulu, Bengkulu, Indonesia

Email: azisabdulmalikmalik@gmail.com

\begin{abstract}
ABSTRAK
Taman nasional merupakan salah satu kawasan konservasi terbaik untuk menyaksikan keindahan fenomena alam terutama untuk flora dan fauna endemik, langka dan dilindungi (Kementerian Kehutanan, 2003) sehingga keberadaan taman nasional memiliki arti yang sangat strategis dan penting dalam keanekaragaman hayati tari peles. Taman Nasional Bukit Barisan Selatan memiliki keanekaragaman hayati yang sangat kaya. Oleh UNESCO, taman nasional ini ditetapkan sebagai Klaster Situs Warisan. Pegunungan Hutan Hujan Tropis Sumatera (Pegunungan Hutan Hujan Tropis Warisan Situs Klaster Sumatera) bersama dengan Taman Nasional Kerinci Seblat dan Taman Nasional Gunung Leuser. Penelitian ini dilakukan pada bulan April hingga Mei 2020 di Taman Nasional Bukit Barisan Selatan (TNBBS), Kabupaten Bintuhan, Kabupaten Kaur, Provinsi Bengkulu. Penelitian ini bertujuan untuk memperoleh informasi tentang keanekaragaman hayati flora dan fauna Taman Nasional Bukit Barisan Selatan, khususnya di kawasan taman nasional yang memiliki keanekaragaman flora dan fauna. Hasil penelitian menunjukkan bahwa terdapat banyak jenis flora dan fauna yang memiliki keanekaragaman jenis, ditemukan jenis mamalia dan jenis burung, serta tumbuhan di kawasan TNBBS.
\end{abstract}

Kata Kunci: Keanekaragaman Hayati, Flora dan Fauna, Taman Nasional Bukit Barisan Selatan.

\begin{abstract}
The national park is one of the best conservation areas to witness the beauty of natural phenomena, especially to witness endemic, rare and protected flora and fauna (Ministry of Forestry, 2003), so that the existence of a national park has a very strategic meaning. and important in the biodiversity peles dance. Bukit Barisan Selatan National Park has a very rich biodiversity. By UNESCO, this national park was designated a Cluster Heritage Site. Sumatra Tropical Rainforest Mountains (Mountainous Tropical Rainforest Herritage of Sumatra Cluster Site) along with Kerinci Seblat National Park and Gunung Leuser National Park. This study was conducted in April to May 2020 in the Bukit Barisan Selatan National Park (TNBBS), Bintuhan District, Kaur District, Bengkulu Province. This study aims to obtain information about the biodiversity of flora and fauna of the Bukit Barisan Selatan National Park, especially in the national park area which has a variety of flora and fauna. The results showed that there were many species of flora and fauna that had a diversity of species, found species of mammals and species of birds, and plants in the TNBBS area.
\end{abstract}

Keywords: Biodiversity, Flora and Fauna, Bukit Barisan Selatan National Park.

\section{PENDAHULUAN}

Sejarah paleobiogeografi telah membentuk wilayah Indonesia kedalam tiga region utama yaitu Laurasia (dataran Sunda), Gondwana Timur (dataran Australo-Papua), dan Wallacea (wilayah peralihan). Ketiganya mempunyai keaneakaragaman hayati yang khas. kombinasinya menyebabkan Indonesia dikenal sebagai pusat keanekaragaman hayati dunia (Tomascik et al. 1997; Suripto, 2000). Indonesia juga dikenal sebagai negara maritim atau negara kepulauan (archipelago state) terbesar, memiliki panjang garis pantai $95.181 \mathrm{~km}$ (KKP, 2012).

Taman nasional merupakan salah satu kawasan konservasi terbaik untuk me-nyaksikan keindahan fenomena alam, ter-utama untuk menyaksikan flora dan fauna endemik, langka, dan dilindungi (Departemen Kehutanan, 2003), sehingga keberadaan taman nasional memiliki arti yang sangat strategis dan penting dalam peles-tarian keanekaragaman hayati.

Taman Nasional Bukit Barisan Selatan Ditetapkan Pada Tanggal 29 Juni 1999 Oleh Menteri Kehutanan Melalui Kepmenhut No. 489/Kpts-II/199. Letak Geografisnya 
Provinsi Lampung, yang meliputi dua kabupaten yakni Tanggamus dan Lampung Barat Provinsi Bengkulu, tepatnya di daerah Kabupaten Kaur.

\section{Bukit Barisan Selatan Forest Range}
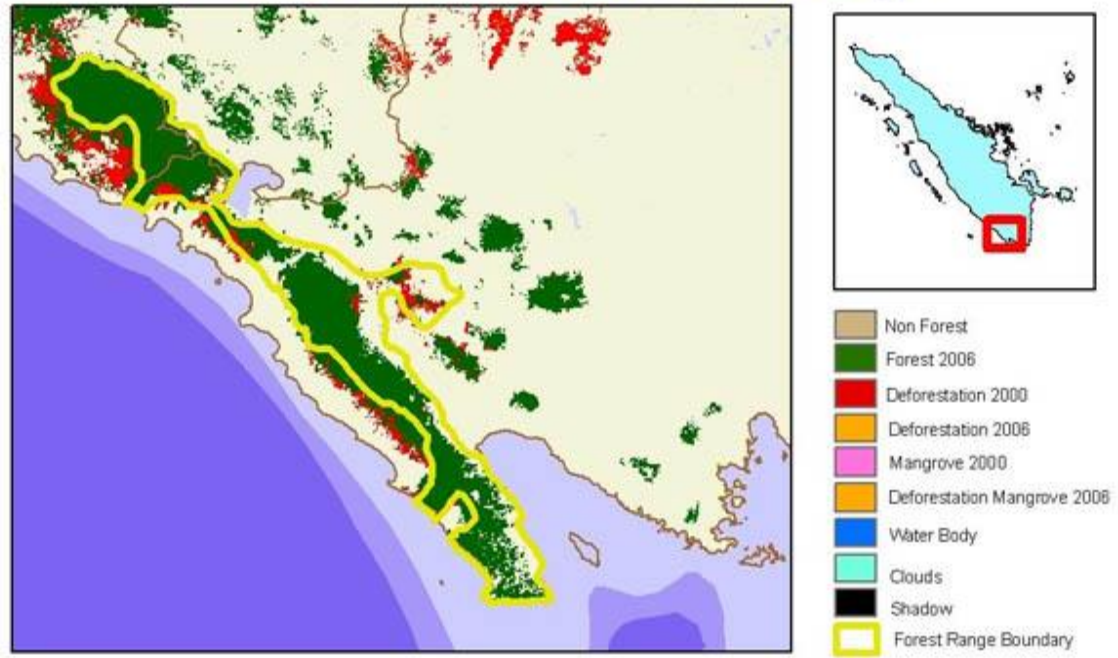

Gambar 1 Lokasi Taman Nasioanl Bukit Barisan Selatan

Sumber gambar ((https://programs.wcs.org/btnbbs))

Taman Nasional Bukit Barisan Selatan memiliki keanekaragaman hayati yang luar biasa kaya. Oleh karena itu, UNESCO menjadikan taman nasional ini sebagai Situs Warisan Gugusan Pegunungan Hutan Hujan Tropis Sumatra (Cluster Mountainous Tropical Rainforest Herritage Site of Sumatera) bersamaan dengan Taman Nasional Kerinci Seblat dan Taman Nasional Gunung Leuser.

Taman Nasional Bukit Barisan Selatan adalah rumah dari tiga satwa paling langka dan kharismatik yaitu badak, gajah, dan harimau sumatera. Taman nasional ini adalah satu dari beberapa areal hutan yang penting untuk konservasi harimau di Asia Tenggara dan rumah dari setengah populasi badak sumatera dan seperempat populasi gajah sehingga tempat ini menjadi wilayah konservasi yang penting di dunia. Taman Nasional Bukit Barisan Selatan terbentang seluas 356.800 hektar dan termasuk dalam daerah administrasi Provinsi Lampung dan Bengkulu. (https://programs.wcs.org/btnbbs)

Kawasan TNBBS merupakan habitat bagi satwa dan tumbuhan baik yang dilindungi maupun tidak dilindungi, memiliki fungsi hidrologis serta sosial ekonomi. Taman Nasional Bukit Barisan Selatan mempunyai kelimpahan kekayaan sumber daya alam hayati dan ekosistemnya yang keberadaannya perlu dilestarikan agar tetap memenuhi fungsinya sebagai kawasan perlindungan sistem penyangga kehidupan, pengawetan keanekaragaman jenis satwa dan tumbuhan beserta ekosistemnya serta pemanfaatan secara lestari sumber daya alam dan ekosistemnya untuk kepentingan pendidikan, penelitian, penunjang budidaya, rekreasi dan wisata alam. Disekitar kawasan TNBBS terdapat masyarakat dan beberapa merupakan enclave. Jumlah desa di sekitar kawasan TNBBS yaitu 124 desa yang tersebar pada 21 kecamatan di Kabupaten Tanggamus, Kabupaten Lampung Barat (Provinsi Lampung), dan Kabupaten Kaur (Provinsi Bengkulu).

Flora di wilayah Indonesia merupakan bagian dari flora Malesiana. Ditinjau dari wilayah biogeografi, setidaknya terdapat tujuh wilayah biogeografi utama Indonesia yang menjadi wilayah penyebaran berbagai spesies tumbuhan, yaitu Sumatra, Jawa dan Bali, Kalimantan, Sunda Kecil, Sulawesi, Maluku dan Irian Jaya (BAPPENAS 1993).

Indonesia merupakan negara kepulauan yang terletak di kawasan tropis antara dua benua yaitu (Benua Asia dan Benua Australia) serta berada di antara dua Samudera yakni (Samudera Hindia dan Samudera Pasifik) yang terdiri atas sekitar 17.500 pulau dengan panjang garis pantai sekitar 95.181 $\mathrm{km}$. Wilayah Indonesia luasnya sekitar 9 juta $\mathrm{km} 2$ (2 juta $\mathrm{km} 2$ daratan, dan 7 juta $\mathrm{km} 2$ lautan). Luas wilayah Indonesia ini hanya sekitar 1,3\% dari luas bumi, namun mempunyai tingkat keberagaman kehidupan yang sangat tinggi. Tumbuhan Indonesia diperkirakan memiliki $25 \%$ dari spesies 
tumbuhan berbunga yang ada di dunia atau merupakan urutan negara terbesar ketujuh dengan jumlah spesies mencapai 20.000 spesies, $40 \%$ merupakan tumbuhan endemik atau tumbuhan asli Indonesia. Famili tumbuhan yang memiliki anggota spesies paling banyak adalah Orchidaceae (anggrek-anggrekan) yakni mencapai 4.000 spesies. Untuk jenis tumbuhan berkayu, famili Dipterocarpaceae memiliki 386 spesies, anggota famili Myrtaceae (Eugenia) dan Moraceae (Ficus) sebanyak 500 spesies dan anggota famili Ericaceae sebanyak 737 spesies, termasuk 287 spesies Rhododendrom serta 239 spesies Naccinium “Whitemore 1985 dalam Santoso 1996”

Untuk jenis paku-pakuan, Indonesia juga tercatat memiliki keanekaragaman spesies yang tinggi mencapai lebih 4000 spesies tersebar hampir di seluruh wilayah Nusantara.Untuk jenis rotan, tercatat ada sekitar 332 spesies terdiri dari 204 spesies dari Genera Calamus, 86 spesies dari Genera Daemonorps, 25 spesies dari genera Korthalsia, 7 spesies dari genera Ceratolobus, 4 spesies dari genera Plectocomia, 4 spesies dari Genera Plectocomiopsis, serta 2 spesies dari Genera Myrialepsis. Selain itu banyak juga jenis-jenis keanekaragaman tumbuhan yang dapat dimanfaatkan sebagai obat di Indonesia. Menurut catatan WHO sekitar 20.000 spesies tumbuhan dipergunakan oleh penduduk dunia sebagai obat. Zuhud \& Haryanto (1994) mencatat ada sekitar 1.260 spesies tumbuhan yang secara pasti diketahui berkhasiat obat. Indonesia juga tercatat sebagai salah satu pusat Vavilov yaitu pusat sebaran keanekaragaman genetik tumbuhan budidaya/pertanian untuk tanaman pisang (Musa spp.) pala (Myristica fragrans), cengkeh (Syzygium aromaticum), durian (Durio spp.) dan rambutan (Nephelium spp.) Indonesia adalah pusat keanekaragaman pisang didunia (Nasoetion, 1991).

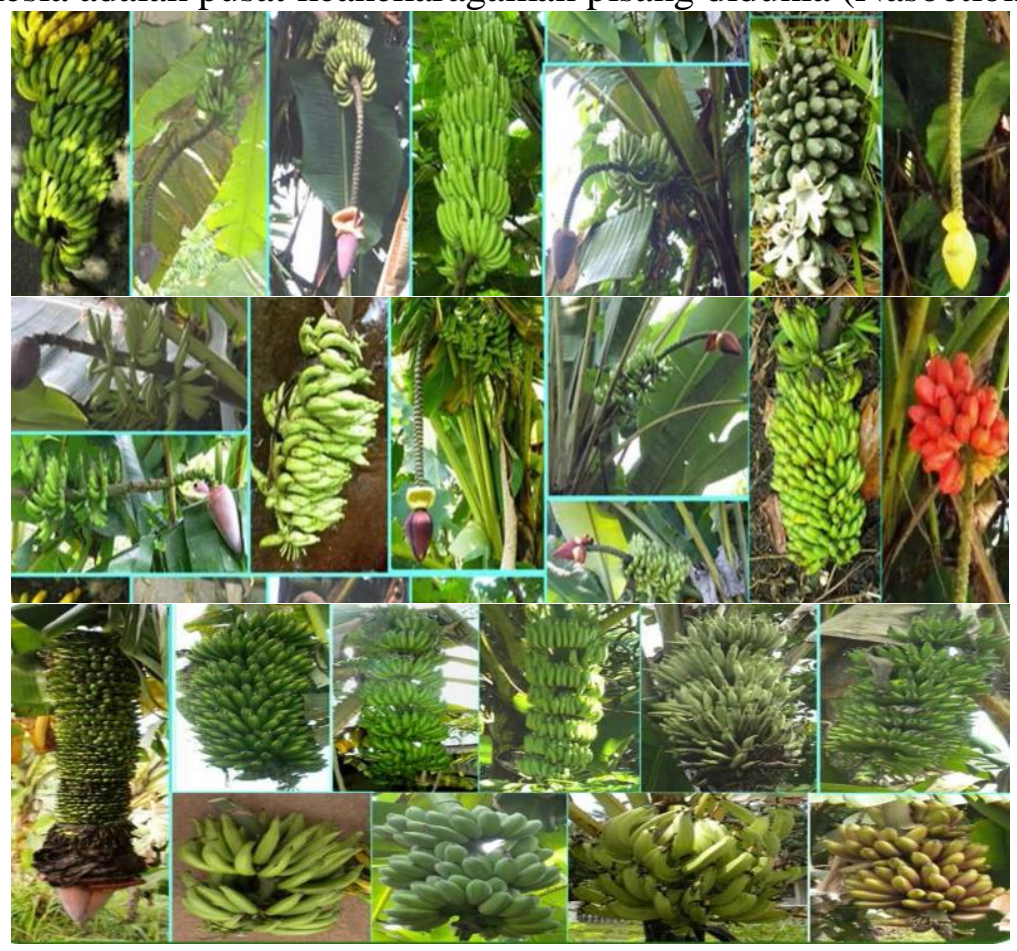

Gambar 2. Keanekaragaman pisang di Indonesia

Sumber gambar (LIPI, 2013)

Hutan Indonesia juga diketahui memiliki keanekaragaman jenis pohon palem (Arecaceae) tertinggi di dunia, lebih dari 400 spesies (70\%) pohon meranti (Dipterocarpaceae) terbesar di dunia sebagai jenis kayu tropika primadona, dan memiliki 122 spesies bambu dari 1.200 spesies bambu yang tumbuh di bumi. Tingginya kekayaan keanekaragaman tumbuhan tersebut juga ditunjukkan oleh kekayaan di hutan Kalimantan. Misalnya, dalam satu hektar dapat tumbuh lebih dari 150 spesies pohon yang berlainan, tercatat 3.000 spesies pohon, serta memiliki 19 dari 27 spesies durian yang terdapat di kawasan Melanesia. Indonesia juga memiliki lebih dari 350 jenis rotan dan merupakan penghasil $3 / 4$ rotan dunia.

Meskipun dari jumlah spesies tumbuhan, Indonesia tercatat sebagai negara dengan kekayaan tumbuhan yang tinggi, namun sayang potensi sumberdaya genetik yang terkandung di dalamnya belum diketahui semuanya. Hanya sebagian kecil spesies tumbuhan yang telah diketahui informasi 
sumber daya genetiknya, terutama untuk jenis-jenis yang telah dikembangkan pemanfaatannya secara komersial. "Cecep Kusmana, Agus Hikmat. 2015"

Eksploitasi terhadap keanekaragaman hayati, penebangan liar, konversi kawasan hutan menjadi area lain, perburuan dan perdagangan liar merupakan beberapa faktor yang menyebabkan terancamnya keanekaragaman hayati. Usaha yang dapat mendorong penyelamatan sumber daya alam yang ada, dan adanya realitas meningkatnya keterancaman dan kepunahan sumber daya hayati, maka ditetapkan adanya status kelangkaan suatu spesies. Indonesia merupakan negara dengan tingkat keterancaman dan kepunahan spesies tumbuhan tertinggi di dunia dan merupakan hot-spot kepunahan satwa. Tercatat sekitar 240 spesies tanaman dinyatakan langka, diantaranya banyak yang merupakan spesies budidaya. Paling sedikit 52 spesies keluarga anggrek, 11 spesies rotan, 9 spesies bambu, 9 spesies pinang, 6 spesies durian, 4 spesies pala, dan 3 spesies mangga (Mogea et al. 2001). Selain itu ada 44 spesies tanaman obat dikategorikan langka, seperti pulasari, kedawung, jambe, pasak bumi, gaharu, sanrego "Rifai et al. 1992; Zuhud et al. 2001)."

Bahkan "Whitten (1994) dalam Suhirman et al.(1994)” menduga bahwa tiga spesies anggrek endemik Jawa telah punah, yaitu spesies Habenaria giriensis, Plocoglottis latifolia dan Zeuxine tjiampeana.

Berdasarkan "Peraturan Pemerintah RI No.7 Tahun 1999" terdapat tidak kurang dari 58 spesies tumbuhan yang termasuk kedalam 6 famili termasuk kategori dilindungi, diantaranya yaitu keluarga talas-talasan (miss. Amorphohalus 38itanium), palem (Ceratolobus glaucencens), anggrek (Phalaenopsis javanica), kantong semar (Nephenthes spp.), bunga patma (Rafflesia spp) dan meranti (Shorea spp.).

Kissinger (2013) menyatakan bahwa salah satu informasi penting yang diperlukan untuk mendukung pengelolaan yang baik terhadap sumberdaya tumbuhan yaitu teridentifikasikannya karakteristik habitat dan fenotif, sehingga akan menjadi dasar bagi tindakan konservasi. Kelengkapan informasi merupakan faktor yang penting dalam menyusun rencana konservasi dan strategi pengelolaan sumber daya alam hayati "Sartika 2017"

Penelitian ini bertujuan untuk memperoleh informasi tentang keanekaragaman hayati flora dan fauna Taman Nasional Bukit Barisan Selatan, terutama pada kawasan taman nasional yang memiliki flora dan fauna yang beragam.

\section{METODE PENELITIAN}

Penelitian dilaksanakan pada bulan April hingga Mei 2020 di kawasan Taman Nasional Bukit Barisan Selatan (TNBBS), Kecamtan Bintuhan, Kabupaten Kaur, Provinsi Bengkulu. Pengambilan data primer dilakukan dengan metode observasi, yaitu dengan berjalan menyusuri hutan di sepanjang garis transek yang telah ditentukan. Selanjutnya dilakukan inventarisasi dan penghitungan tumbuhan hewan yang ada di taman nasional bukit barisan selatan dan perubahan lingkungan yang terjadi. Data yang diambil meliputi jenis-jenis hewan, perubahan lingkungan kawasan taman nasional bukit barisan selatan. Data sekunder diambil melalui wawancara kepada polisi hutan yang sering melakukan observasi disana dalam hal ini bapak Nang Jamadi, Muhammad Ghifari Zakawali, Si, penelusuran kajian pustaka terhadap berbagai studi literatur, baik jurnal, buku, makalah, media maupun informasi dari internet yang berkaitan dengan tema penelitian.

Analisis data dilakukan baik secara kualitatif maupun kuantitatif. Analisis kualitatif dilakukan dengan cara mengkaji dan mendeskripsikan fakta-fakta yang ada dan berkaitan dengan jenis-jenis hewan, kondisi perubahan lingkungan hutan sebagai kawasan konservasi keanekaragaman hayati. Analisis kuantitatif dilakukan dengan cara menganalisis data yang telah diperoleh menggunakan Indeks-indeks ekologik, yaitu Indeks Keanekaragaman Jenis dan Indeks Kemerataan Jenis serta Kerapatan Relatif populasi.

\section{HASIL DAN PEMBAHASAN}

Taman Nasional Bukit Barisan Selatan (TNBBS), merupakan rangkaian pegunungan Bukit Barisan Selatan, yang dikenal keberadaannya sebagai salah satu taman nasional dengan sisa ekosistem hutan dataran rendah yang cukup luas di 
Indonesia (Anonymous, 2008). Jenis tanah di sebagian besar kawasan Taman Nasional Bukit Barisan Selatan (TNBBS) adalah podsolik merah kuning yang dikenal labil dan rawan erosi.

Taman Nasional Bukit Barisan Selatan (TNBBS) merupakan perwakilan dari rangkaian pegunungan Bukit Barisan yang terdiri dari tipe vegetasi hutan mangrove, hutan pantai, hutan pamah tropika sampai pegunungan di Sumatera.

Secara umum telah teridentifikasi paling sedikit 514 jenis pohon, tumbuhan bawah sekitar 98 jenis dari famili antara lain Dipterocarpaceae, Lauraceae, Myrtaceae, Fagaceae, Annonaceae, Rosaceae, Zingiberaceae dan lain-lain serta 126 jenis anggrek, 26 jenis rotan, 24 jenis liana dan 15 jenis bambu yang hidup di daerah Taman Nasional Bukit Barisan Selatan (TNBBS). Berdasarkan data FIMP untuk tanaman obat telah teridentifikasi sebanyak 124 jenis yang tersebar di kawasan Taman Nasional Bukit Barisan Selatan (TNBBS).

Kawasan Taman Nasional Bukit Barisan Selatan (TNBBS) merupakan habitat bagi jenis-jenis tumbuhan berbunga unik, langka dan masih ada dalam proses evolusi diantaranya bunga Rafflesia (Rafflesia sp) dan dua (2) buah jenis bunga bangkai masing-masing Amorphophallus titanum dan Amorphophallus deculsivae. Amorphophallus titanium, disebut juga bunga bangkai jangkung tingginya dapat mencapai 2 meter.

Ditemukan juga Kantong semar (Nepenthes spp.) merupakan tumbuhan karnivora yang mampu menjebak serangga dan hewan kecil lainnya, organ tersebut berupa kantong (Mansur 2012). Di Indonesia ditemukan sebanyak 64 spesies Nepenthes spp. (Handoyo dan Sitanggang 2006). Khususnya di Provinsi Kepulauan Bangka Belitung terdapat lima jenis murni dan dua jenis hasil persilangan alami "Rizqiani 2018 "

Rafflesia spp. merupakan salah satu marga tumbuhan yang dilindungi berdasarkan Peraturan Pemerintah No.7 Tahun 1999. Pada eksplorasi ini, satu jenis Rafflesia berhasil dikoleksi tetapi tidak belum dapat diidentifikasi jenisnya berdasarkan karakter morfologi. Karena persebaran Rafflesia sangatlah terbatas dan siklus hidupnya menghabiskan waktu yang sangat lama maka tumbuhan ini termasuk dalam kategori langka dan harus dilindungi. Dengan ditemukannya satu jenis Rafflesia di kawasan ini, kemungkinan dapat ditemukan individu-individu lain dari jenis Rafflesia tersebut.

Nepenthes spp. memiliki keunikan sehingga dijadikan tanaman hias di Indonesia. Keunikan yang menjadikan Nepenthes spp. sebagai tanaman hias yaitu bentuk dan warna kantong yang bervariasi. Keragaman morfologi dapat digunakan untuk pengelompokkan antar spesies kantong semar (Selviana et al. 2018). Keragaman morfologi juga dapat disebabkan faktor lingkungan yang turut mempengaruhi perubahan morfologi Nepenthes spp.. Kondisi lingkungan yang berbeda mengakibatkan perubahan pola morfologi tumbuhan sehingga akan terbentuk sifat-sifat yang berbeda (Selviana et al. 2018).

Tumbuhan lain yang menjadi ciri khas dari taman nasional ini yaitu tanaman anggrek raksasa/tebu (Grammatophylum speciosum). Berdasarkan hasil inventarisasi, terdapat sebanyak 157 jenis tumbuhan di Taman Nasional Bukit Barisan Selatan yang dapat digunakan sebagai tanaman obat, seperti pasak bumi (Eurycoma longifolia), dan pulai (Alstonia scholaris). Taman Nasional ini juga merupakan habitat bagi jenis-jenis tumbuhan endemik dilindungi dan langka, yaitu bunga rafflesia (Rafflesia sp) dan 2 jenis bunga bangkai Amorphophallus titanum dan A. Deculsilvae.

Vegetasi yang dapat dijumpai di TNBBS berbeda-beda untuk setiap tipe ekosistem. Vegetasi yang umum di jumpai di lahan basah dan pesisir yaitu Terminalia cattapa, Hibiscus sp, Baringtonia asiatica, Callophyllum inophyllum, Casuania sp, Pandanus sp, dan Ficus septica.

Hutan hujan dataran rendah di dominasi oleh Shorea sp, Dipterocarpus sp, Hopea $s p$, dengan jenis tumbuhan bawah diantaranya Urophyllum sp, Phrynium sp, Korthalsi sp, danCalamus sp. Hutan hujan bukit didominasi oleh famili Dipterocarpaceae, Lauraceae, Myrtaceae, Annonaceae dengan tumbuhan 
bawah Neolitsea cassianeforia, Psychotria rhinocerotis, Areaca sp, dan Globba pendella.

Selanjutnya, hutan hujan pegunungan bawah di huni oleh jenis-jenis dari keluarga Lauraceae, Myrtaceae, Dipterocarpaceae, Fagaceae seperti Magnolia sp, Quercus $s p$, dan Garcinia sp. Sedangkan hutan hujan pegunungan tingginya didominasi oleh Eugenia sp dan Castanopsis sp. Jenis-jenis sea weed ditemukan di daerah pesisir Selatan Sumatera, seperti Sargasum gracillum, S. echinocarpum, Acanthopora specifesa, Hypnea musciformis, dan Turbinaria ornata, sementara sea weed dan jenis Thallasis sp hidup di sepanjang teluk Belimbing.

Famili pohon yang dominan pada daerah hutan hujan bukit adalah Dipterocarpaceae, Lauraceae, Myrtaceae dan Annonaceae. Kawasan TNBBS juga terdapat habitat penting dari Damar Mata Kucing (Shorea javanica), Damar Batu (Shorea ovalis) serta Jelutung (Dyera $s p$ ).

Kawasan taman nasional ini, merupakan daerah yang memiliki habitat penting bagi berbagai jenis tumbuhan yang memiliki pemanfaatan secara tradisional, seperti jenis penghasil getah damar mata kucing (Shorea javanica), damar batu (S. Ovalis), serta jelutung (Dyera costulata). Selain itu terdapat juga 11 flora endemik Sumatera, yakni Bacaurea multiflora, Madhuca magnifolia, Memecylon multiflorum, Drypetes subsymetrica, Drypetes simalurensis, Ryparosa multinervosa dan lain sebagainya.

Hampir seluruh jenis fauna khas Pulau Sumatera ada di kawasan ini kecuali Orang Utan Sumatera. Secara umum, telah teridentifikasi ada 122 jenis mamalia termasuk 7 jenis primata, 450 jenis burung termasuk 9 jenis burung rangkong, 123 jenis herpetofauna (reptil dan amphibi), 221 jenis insekta/serangga, 7 jenis moluska, 2 jenis krustasea serta 53 jenis ikan yang hidup di kawasan TNBBS.

Satwa yang menghuni Taman Nasional Bukit Barisan Selatan (TNBBS) ini antara lain: Badak Sumatera (Dicerorhinus sumatrensis), Gajah Sumatera (Elephas maximus), Harimau (Panthera tigris), Tapir (Tapirus indicus), Rusa (Cervus sp), Kancil (Tragulus javanicus), Kerbau liar (Bubalus bubalis), Kijang (Muntiacus muntjak), Kambing hutan (Capricorn sumatrensis), Ajak (Cuon alpinus), Ungko (Hylobates agilis), Ular sanca (Phyton reticulatus), dan lain sebagainya. Ada berbagai jenis kera dan monyet yang mendiami di wilayah tersebut. Habitat yang sangat baik di kawasan Taman Nasional Bukit Barisan Selatan ini antara lain: Siamang (Symphalangus syndactylus), Owa (Hylobates agilis), Kera (Macaca fascicularis), Beruk (Macaca nemestrina), Lutung (Presbytis cristata) dan Presbytis melalophos. Di daerah yang lebih dalam, dapat dijumpai pula Beruang Madu (Helarctos malayanus). Berbagai jenis Rangkong (Buceros sp) serta jenis-jenis burung lain juga menjadi bagian dari kekayaan fauna yang tidak dapat dipisahkan.

Di sepanjang pantai selatan dan barat dapat dijumpai beberapa jenis Penyu antara lain: Dermochelys imbricata, Penyu Sisik (Eretmochelys imbricata), dan lain sebagainya. Terdapat 6 jenis binatang mamalia yang terancam menurut Red Data Book IUCN yaitu: Gajah Sumatra (Elephas maximus sumatranus) dengan dugaan populasi diperkirakan 498 ekor (Hedges, et. al, 2005), Badak Sumatra (Dicerorhinus sumatrensis) dengan dugaan populasi diperkirakan 60 - 80 ekor (RPU), Harimau Sumatra (Panthera tigris sumatrensis) dengan dugaan populasi diperkirakan $40-43$ ekor (O’brien dkk, 2003), Tapir (Tapirus indicus), Beruang Madu (Helarctos malayanus, serta Ajag (Cuon alpinus).

\section{SIMPULAN}

\subsection{Simpulan}

Upaya pelestarian sumber daya alam merupakan pengelolaaan untuk mendapatkan keanekaragaman gen yang sebanyak-banyaknya. Adapun usaha tersebut antara lain perlindungan kawasan tertentu yang meliputi cagar alam, suaka margasatwa, hutan lindung, hutan wisata, taman 
nasional, taman nasional, taman laut, dan taman wisata. Usaha pelestarian sumber daya alam hayati yang lain adalah dengan kebun tumbuhan (botani) dan penyimpanan biji atau jaringan khusus tumbuhan dengan teknik tertentu. Selain pelestarian sumber daya alam hayati, ada juga usaha perlindungan sumber daya alam. Salah satunya adalah perlindungan alam dengan taman nasional. Taman nasional yang akan dibahas adalah Taman Nasional Bukit Barisan Selatan (TNBBS).

Keanekaragaman Hayati Kawasan ini memiliki keanekaragaman jenis hayati (biodiversity) yang sangat tinggi baik flora maupun fauna. Potensi flora TNBBS meliputi 514 jenis pohon dan tumbuhan bawah, 26 jenis rotan, 15 jenis bambu serta 126 jenis anggrek termasuk 2 jenis tumbuhan langka yaitu bunga bangkai (Amorphophallus sp) serta bunga rafflesia (Rafflesia sp). Berdasarkan hasil identifikasi, sebanyak 137 jenis tumbuhan di TNBBS dapat digunakan sebagai tanaman obat. Sementara itu, Fauna yang telah teridentifikasi adalah 115 jenis mamalia, 7 jenis primata, 450 jenis burung, 9 jenis burung rangkong, 123 jenis herpetofauna (reptil dan amphibi), 221 jenis insekta/serangga, 7 jenis moluska, 2 jenis krustasea serta 53 jenis ikan. Obyek Wisata Alam Selain kekayaan flora dan fauna kawasan ini juga kawasan ini juga memiliki keindahan alam yang sangat menarik, seperti : Sukaraja Atas, habitat bunga raflesia (Rafflesia sp), bunga bangkai raksasa (Amorphophallus sp), satwa lair primata dan burung. Keramat Menula, Potensi wisata yang ada meliputi hutan hujan dataran rendah primer, pantai karang, makam keramat Syech Aminullah, satwa liar primata dan berbagai jenis burung.

\subsection{Saran}

Untuk mengungkap keanekaragaman hayati flora dan fauna yang lebih besar, perlu dilakukan kajian secara komprehensif dan menyeluruh. Kajian ilmiah terhadap keanekaragaman hayati sangat diperlukan guna memonitoring dan mengetahui jenis sepsis apa saja yang hidup ditaman nasional bukit barisan selatan saat ini, mempelajari ancaman, menemukan solusi permasalahan terbaik, sampai dengan pengelolaan pemanfaatan untuk pengembangan berkelanjutan dimasa mendatang.

Untuk mencapai tujuan pengembangan berkelanjutan, diperlukan perhatian serius terhadap upaya kelola dan pemanfaatan taman nasional dalam bentuk, pelestarian flora dan fauna dan rehabilitasi yang terdegradasi, peningkatan daya dukung lingkungan, penataan ruang dan integrasi antar sumber daya alam, sumber daya buatan, dan sumber daya manusia di wilayah TNBBS, serta peningkatan peran serta masyarakat.

\section{DAFTAR PUSTAKA}

Armanda, Anggraeni Dan Tri Wahyuni. 2020. Populasi Dan Karakterisasi Fenotip Kantong Semar (Nepenthes Spp.) Di Taman Keanekaragaman Hayati Hutan Pelawan Kabupaten Bangka Tengah, Provinsi Kepulauan Bangka Belitung. Media Konservasi Vol. 25 No. 1 April 2020: 89-97

[BAPPENAS] Badan Perencana Pembangunan Nasional.1993. Biodiversity Action Plan for Indonesia. Jakarta: BAPPENAS.

Cecep Kusmana, Agus Hikmat. 2015. The Biodiversity of Flora in Indonesia. Jurnal Pengelolaan Sumberdaya Alam dan Lingkungan Vol. 5 No. 2

(Desember 2015): 187-198

Departemen Kehutanan. 2003. 41 Taman Nasional di Indonesia. Departemen Kehutanan. Jakarta.

Handoyo, Sitanggang. 2006. Perawatan Praktis Kantong Semar. Jakarta: PT. Grafindo Persada

Indra A. S. L. P. Putri dan Merryana Kiding Allo. 2009. Degradasi Keanekaragaman Hayati Taman

Nasional Rawa Aopa Watumohai (Biodiversity Degradation Of Rawa Aopa Watumohai National Park). DOI: 10.20886/jphka.2009.6.2.169-194

Kissinger. 2013. Bioprospeksi hutan kerangas: Analisis Nepenthes gracilis Korth sebagai stimulus konservasi [disertasi]. Bogor: Institut Pertanian Bogor.

Mansur M. 2012. Laju penyerapan CO2 pada kantong semar (Nepenthes gymnamphora Nees) di Taman Nasional Halimun Salak, Jawa Barat. Jurnal Teknik Lingkungan. 13(1):59-65.

Peraturan Pemerintah RI No. 7 Tahun 1999. Tentang Jenis-jenis Tumbuhan dan Satwa yang Dilindungi.

Rifai MA, Rugayah, Widjaja EA (Eds.). 1992. Tiga Puluh Tumbuhan Obat Langka Indonesia. Penggalang Taksonomi Tumbuhan Indonesia, Bogor. 
Rizqiani. 2018. Keanekaragaman kantong semar (Nepenthes) di Kepulauan Bangka Belitung [tesis]. Bogor: Institut Pertanian Bogor.

Sartika. 2017. Population and distribution pattern kantong semar (Nepenthes gracilis) in Rhino Camp Resort Sukaraja Atas Region Bukit Barisan Selatan Nasional Park (BBSNP). Jurnal Siylva Lestari. 5(3):12-21.

Selviana A, Turnip R, Linda R. 2018. Variasi morfometrik dan pengelompokan spesies kantong semar (Nepenthes spp.) di Desa Simpang Kasturi Kecamatan Mandor. Protobiont. 7(2):29-36.

Suripto, B.A. 2000. Keanekaragaman hayati di pukau-pulau kecil di Indonesia: asal-usul mereka, statusnya kini dan nasibnya yang akan datang. Prosiding Seminar Nasional Pengelolaan Ekosistem Pantai Dan Pulau. Pulau Kecil Dalam Konteks Negara Kepulauan. Yogyakarta : Fakultas Geografi UGM.

TNBBS. 21 oktober. 2019. Terbaru: Keanekaragaman flora dan fauna di Taman Nasional Bukit Barisan

Selatan .http://programs.wcs.org/btnbbs/BeritaTerbaru/articleType/ArticleView/atcled/6877/KEANE KARAGAMAN FLORA-DAN-FAUNA-DITNBBS.aspx. diakses Monday,4 April 20, 2020, 12:08:42 PM

Zuhud EAM, Haryanto. 1994. Pelestarian Pemanfaatan Keanekaragaman Tumbuhan Obat Hutan Tropika Indonesia. Fakultas Kehutanan IPB, Bogor.

Wira Rahardi, Rizal M. Suhardi.2016. Keanekaragaman Hayati dan Jasa Ekosistem Mangrove Di Indonesia.Prosiding Symbion (Symposium on Biology Education), Prodi Pendidikan Biologi, FKIP, Universitas Ahmad Dahlan, 27 Agustus 2016 hal 500- 510. 